\title{
ALTERNATIVE METHODS FOR ACCELERATING THE RATE OF ORTHODONTIC TOOTH MOVEMENT: LITERATURE REVIEW
}

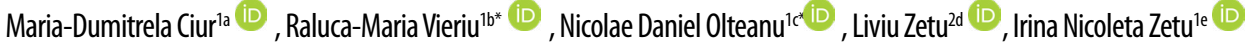 \\ 'Department of Orthodontics and Dentofacial Orthopedics, Faculty of Dental Medicine, "Grigore T. Popa"University of Pharmacy, lași, Romania \\ 2Department of Odontology and Periodontology, Faculty of Dental Medicine, "Grigore T. Popa” University of Medicine and Pharmacy, lași, Romania
}

aDM, PhD, Private practice

${ }^{b} \mathrm{DMD}, \mathrm{PhD}$, Assistant professor

'DMD, PhD student, Assistant professor

${ }^{\mathrm{D} D M D}$, PhD, Lecturer

EDMD, PhD, Professor

\begin{abstract}
DOI: https://doi.org/10.25241/stomaeduj.2019.6(3).art.3

Background: The rate of orthodontic tooth movement depends on two general factors: the forces used in order to cause orthodontic tooth movement and respectively the individual (biological) response of the body to these forces.

Objective: The aim of this review is to offer an overview of the factors that has been mentioned in literature to accelerate the biologic response to orthodontic forces.

Data Sources: PubMed, Google Scholar and Scopus databases were used.

Study selection: We included in our study controlled clinical trials, but also randomized controlled trials and even cases series with more than 5 subjects that aimed to evaluate alternatives methods in accelerating the rate of orthodontic tooth movement. Publications published until April 2018 were included.

Data Extraction: All the factors that had been mentioned in literature to have a positive influence on the rate of orthodontic tooth movement were synthesized and described as a review. These methods are the followings: physical, surgical and chemical agents. Physical factors are easy to apply, surgical factors are invasive and the pharmacological agents we described in this article are: prostaglandin E2 (PGE2) and vitamin D3.
\end{abstract}

Data Synthesis: The alternatives methods that accelerate the rate of orthodontic tooth movement modulate the biologic response of the periodontal ligament to the mechanical forces. Vitamin D3 was mentioned as the most biopotent agent in accelerating the rate of orthodontic treatment. Although it has biomodulator effect on bone tissue, supplementary studies are needed in order to clarify what is the exact reduction of orthodontic treatment period.

Keywords: Accelerated orthodontic tooth movement; Rate of orthodontic tooth movement; Orthodontic treatment; Biologic response.

\section{Introduction}

Recently, it has been mentioned in literature many methods for accelerating the rate of orthodontic tooth movement. The rate of orthodontic tooth movement depends on the forces used in order to cause orthodontic tooth movement and the individual response (the biological response) of the body to these forces.

Regarding the optimal forces used in order to determine the orthodontic tooth movement, Schwarz established that the forces used to move the teeth must be equal to the capillary pressure on the periodontal ligament. The forces situated below this threshold do not cause any tooth movement, while the forces that exceed this level cause avascular area on the periodontal ligament. While the forces are applied on the tooth, the resorption process is directly influenced by the number of the recruited osteoclasts in the local area [1].

Secondary, the cell response of the body to orthodontic tooth movement can be accelerated by many factors.

The aim of this article was to update the information mentioned in literature regarding the possibilities to accelerate orthodontic tooth movement.

\section{Methodology}

A literature search in PubMed, Google Scholar and Scopus databases was performed in order the find randomized controlled trials, controlled clinical trials, clinical cases with at least 5 subjects that aimed to evaluate the alternatives methods that accelerate the 
rate of orthodontic tooth movement. Publications published until April 2018 were included. We used the following keywords: (drugs OR medicaments OR pharmacological agents OR vibratory stimulation OR surgical methods) and (accelerated orthodontic tooth movement OR increased orthodontic tooth movement). The factors that can influence positively the rate of orthodontic tooth movement are presented in a form of literature review.

\section{Results}

\subsection{Physical stimuli}

Physical stimuli used in association with active orthodontic tooth movement in order to accelerate the rate of orthodontic tooth movement are the following: photobiomodulation, low level laser therapy, low frequency electromagnetic fields, vibrations, low-intensity pulsed ultrasound.

Low level laser therapy and low-intensity pulsed ultrasound were used in order to accelerate orthodontic tooth movement because they have bio-stimulatory effects [2]. In cell-culture experiments, it has been shown that low-intensity pulsed ultrasound application cause an effect on osteoblastic cells. These osteoblastic cells respond by producing local factors: bone morphogenetic proteins (BMP), growth factors (FGF, TGF-beta), and cytokines (IL). These local factors trigger new osteoblastic cells. Also, it has been shown that lowintensity pulsed ultrasound application has an effect on osteoclastic cells in cell-culture experiments. Moreover, the studies that were done on animals, shown that the application of low-intensity pulsed ultrasound caused an acceleration of the process that lead to new bone formation.

The pulsed electromagnetic fields (PEMFs) application influence bone metabolism [3]. Several studies demonstrated that electromagnetic fields accelerate the bone formation.

\subsection{Surgical procedures}

Several surgical procedures were performed in order to reduce the rate of orthodontic treatment: corticotomy, dental distraction, piezocision, section of the periodontal ligament.

Alternatives methods used in association with conventional orthodontic therapy cause an augmentation of the rate of orthodontic tooth movement compared with orthodontic treatment only. This phenomenon is related to the effect of stimulation of bone turnover and also to accelerated cellular activity in the periodontal ligament [4].

\subsection{Pharmacological agents}

Regarding the pharmacological agents that contribute to the acceleration of the rate of orthodontic treatment mentioned in literature we cite: PGE2, vitamin D, parotid hormone, and thyroxine.

Prostaglandin E2 (PGE2) is one of the most studied pharmacological agent implicated in bone turnover which has an important role in the inflammatory process. Their effect on the rate of orthodontic tooth movement was studied by various researchers using animals like monkeys or rats [5-8]. The results of their studies shown that experimental tooth movement was greater compared with the rate of control tooth after one single application or after multiple application, the rate of the tooth movement of the experimental tooth being depended of the administrated dose of PGE2 [5-8]. The action mechanism of the PGE2 is explained through the stimulation process of bone resorption acting directly on osteoclastic cells [9].

Vitamin D3 (calcitriol or 1,25 dihidroxicolecalciferol) is the active form of the vitamin D which is formed on dermis or it is obtained from alimentary sources and after the two hydroxylation on the liver and kidney respectively convert into the active form of vitamin D3 (calcitriol or 1,25 dihidroxicolecalciferol). Vitamin D3 in association with calcitonin and parotid hormone are implicated in regulation of the fosfocalcic homeostasis. Moreover, vitamin D3 in its active form stimulates bone apposition and it has been shown that vitamin $D$ receptors present both the osteoblastic and osteoclastic cells [8].

Studies in vivo shown an augmentation of orthodontic tooth movement after local administration of vitamin D3 [10,11,12]. These augmentations is related to both the role of the vitamin D3 in inducing osteoblastic cells proliferation [13] and stimulating osteoclastic cells activity [13]. The rate of orthodontic tooth movement for the experimental tooth was $60 \%$ greater than the rate of orthodontic tooth movement measured on control tooth.

Humans studies that demonstrate the clinically efficiency of locally administration of calcitriol in acceleration the rate of orthodontic tooth movement are reduced and inconclusive. In this regard, the only article one humans which evaluates the clinical efficacy of locally administrated calcitriol in accelerating the rate of orthodontic tooth movement is the article published by Al Hasani et al in 2011. The results of their study shown a rate of tooth movement grater with a percentage equal of $51 \%$ for the experimental tooth compared to the controls tooth [14].

The association of alternatives methods with conventional orthodontic therapy benefits of some advantages like: accelerated tooth movement, reduced treatment period time and even greater stability of the results obtained after orthodontic treatment. Physical stimuli are easy the applicate but necessitate special devices. Surgical procedures determine rapid tooth movements, but are invasive methods. As regarding the pharmacological agents, they are easy to administrate. Of all the pharmacological agents mentioned in this article, locally administration of calcitriol is the promisive way to reduce orthodontic treatment time. Vitamin D3 in its active biological form has several benefits when 
is locally administrated: stimulates bone resorption inherent for any therapeutic tooth movement and promote bone apposition, helping optimizing the ratio between resorption and apposition in the periodontal ligament. In this way, the biological response to the biomechanical forces is optimized. Other agents, like prostaglandin E2 has an important effect in accelerating orthodontic tooth movement even when it is administrated on a single dose mode, but it has also a secondary effects, being responsible for inducing root resorption on experimental tooth. That's why the studies were reduced only to animals and were not been extended to humans beings.

\section{Limitations of the current analysis}

The articles that met the inclusion criteria were few because the randomized controlled trials, controlled clinical trials and respectively clinical cases with more than 5 subjects included that aimed to accelerate the orthodontic tooth movement are few.

\section{Conclusions}

Of all the alternatives methods presented in this article, locally administrated calcitriol (vitamin D3)

\section{References}

1. Zetu IN, Zetu L. Contention. In: Matei S, Stan E, editors. [Orthodontics and straight wire technique]. Second edition. [in Romanian]. Târgu Mureș, RO: Publishing House Lyra; 2003. 2. Xue $H$, Zheng J, Cui $Z$, et al. Low-intensity pulsed ultrasound accelerates tooth movement via activation of the BMP-2 signaling pathway. PLoS One. 2013;8(7):e68926. [Full text links] [CrossRef] [PubMed] Google Scholar Scopus 3. Dogru M, Akpolat V, Dogru AM, et al. Examination of extremely low frequency electromagnetic fields on orthodontic tooth movement in rats. Biotechnol Biotechnol Equip. 2014; 28(1):118-122. [Full text links] [CrossRef] [PubMed] Google Scholar Scopus 4. Collins MK, Sinclair PM. The local use of vitamin D to increase the rate of orthodontic tooth movement. Am J Orthod Dentofac Orthop. 1988;94(4):278-284. [Full text links] [CrossRef] [PubMed] Google Scholar Scopus 5. Stark M, Sinclair PM. Effect of pulsed electromagnetic fields on orthodontic tooth movement. Am J Orthod Dentofacial Orthop. 1987;91(2):91-104. [Full text links] [CrossRef] [PubMed] Google Scholar Scopus 6. Yamasaki K, Shibata Y, Fukuhara T. The effect of prostaglandins on experimental tooth movement in monkeys. J Dent Res. 1982;61(12):1444-1446. [Full text links] [CrossRef] [PubMed] Google Scholar Scopus 7. Leiker BJ, Nanda RS, Currier GF, et al. The effects of exogenous prostaglandins on orthodontic tooth movement in rats. Am J Orthod Dentofacial Orthop. 1995;108(4):380-388. [Full text links] [CrossRef] [PubMed] Google Scholar Scopus 8. Klein DC, Raisz LG. Prostaglandins: stimulation of bone resorption in tissue culture. Endocrinology. 1970; 86(6):1436-1440. [CrossRef] [PubMed] Google Scholar Scopus seems to be the most promisive way to accelerate the orthodontic treatment: it is an easy method to realize, it has no secondary effect. Although the results of previous study mentioned its important role in the biology of orthodontic tooth movement, the information regarding the overall reduced treatment period are absents. It will be interesting studying the amount of reduced orthodontic treatment period caused by locally administration of vitamin D3 and comparing this period to the one in which patients are following orthodontic treatment only.

\section{Conflict of interest statement}

The authors declare no conflict of interest.

\section{Author Contributions}

MDC, OND, LZ: wrote the manuscript. RMV, INZ: critically revised the manuscript.
9. Seifi M, Eslami B, Saffar AS. The effect of prostaglandin E2 and calcium gluconate on orthodontic tooth movement and root resorption in rats. Eur J Orthod. 2003;25(2):199-204. [Full text links] [CrossRef] [PubMed] Google Scholar Scopus 10. Diravidamani K, Sivalingam SK, Agarwal V. Drugs influencing tooth movement: An overall review. J Pharm Bioallied Sci. 2012;4(Suppl 2):S299-S303. [Full text links] [CrossRef] [PubMed] Google Scholar 11. Raisz LG, Trummel CL, Holick MF, DeLuca HF. 1,25-dihydroxycholecalciferol: a potent stimulator of bone resorption in tissue culture. Science. 1972;175(4023):768-769. [Full text links] [CrossRef] [PubMed] Google Scholar Scopus 12. Takano-Yamamoto T, Kawakami M, Kobayashi Y, et al. The effect of local application of 1,25-dihydroxycholecalciferol on osteoclast numbersinorthodonticallytreatedrats.JDentRes. 1992;71(1):53-59. [Full text links] [CrossRef] [PubMed] Google Scholar Scopus 13. Kale S, Kocadereli I, Atilla P, Așan E. Comparison of the effects of 1,25-dihydroxycholecalciferol and prostaglandin E2 on orthodontic tooth movement. Am J Orthod Dentofac Orthop. 2004;125(5):607-614. [Full text links] [CrossRef] [PubMed] Google Scholar Scopus 14. Al-Hasani NR, Al-Bustani Al, Ghareeb MM, Hussain SA Clinical efficacy of locally injected calcitriol in orthodontic tooth movement. Int J Pharm Pharm Sci. 2011;3(5):139-143. Google Scholar Scopus 
Maria-Dumitrela CIUR

DMD, PhD, Researcher

Department of Orhtodontics and Dento-Facial Orthopaedics Faculty of Dental Medicine "Grigore T. Popa" University of Pharmacy and Medicine

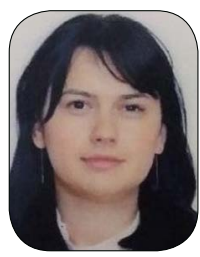

Maria-Dumitrela Ciur is researcher in the field of Medicine and specialist in Orhtodontics and Dento-Facial Orthopaedics at the Faculty of Dental Medicine, "Grigore T. Popa" University of Pharmacy and Medicine, lasi, Romania. She became a PhD Student in 2012 at the Department of Odontology-Periodontology and Department of Normal and Pathological Physiology," "GrigoreT. Popa" University of Pharmacy and Medicine, lași, Romania. She studied four months at University Claude Bernard Lyon 1. She became specialist in Orthodontics and Dentofacial Orthopedics in 2016 and Doctor of Medicine in 2017. For the moment, she practice in private dental medicine.

\section{Questions}

\section{The most biopotent agent in accelerating the rate of orthodontic treatment is:}

口a. Vitamin D3;

ab. Vitamin C;

口c. Vitamin D;

口d. Vitamin A.

\section{The surgical procedures performed in order to reduce the rate of orthodontic} treatment are the folllowing, with one exception:

Da. Corticotomy;

ab. Administration of calcium;

ac. Piezocision;

d. Dental distraction.

3. The pharmacological agents that contribute to the acceleration of the rate of orthodontic treatment are folllowing, with one exception:

Da. PGE2;

ab. Vitamine $D$;

Uc. Vitamin B;

Ud. Parotid hormone.

\section{The association of alternatives methods with conventional orthodontic therapy benefits have the following advantages, with one exception:}

口a. Increased treatment period time;

b. Accelerated tooth movement;

$\square$ c. Reduced treatment period time;

$\square$ d. Greater stability of the results obtained after orthodontic treatment.

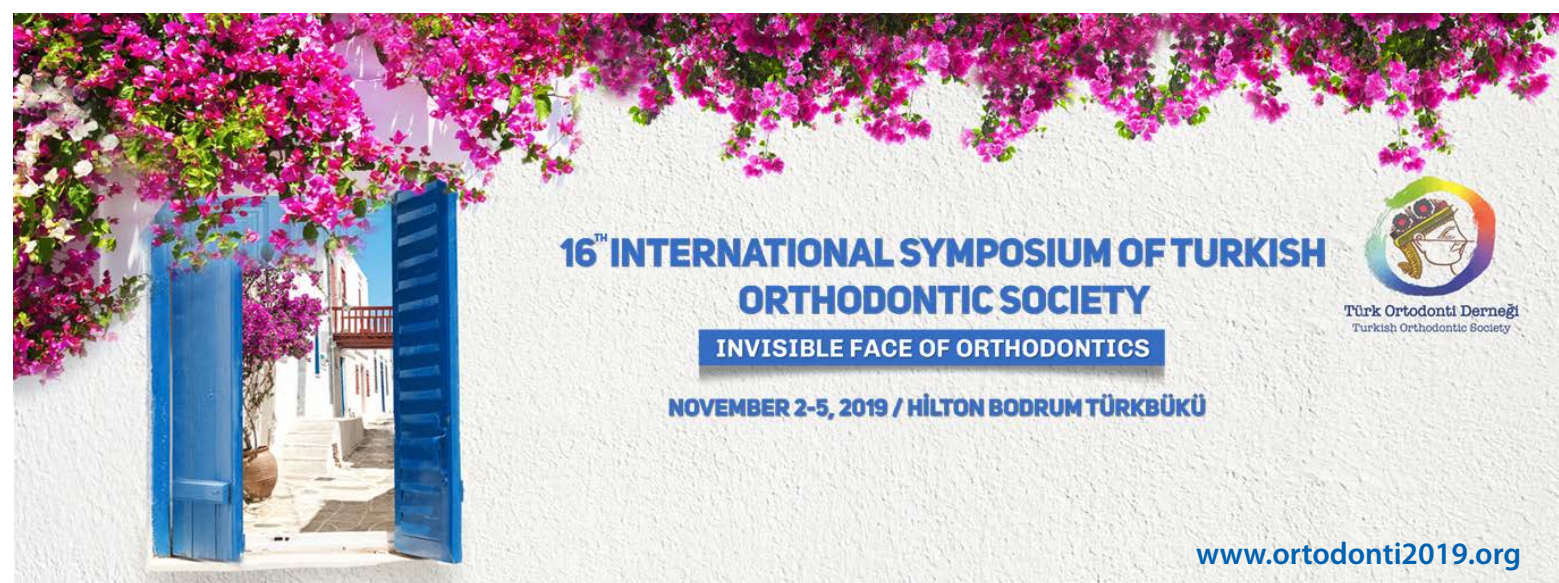

